\title{
Corrigendum: Precision Medicine and Global Health: The Good, the Bad, and the Ugly
}

\section{OPEN ACCESS}

Approved by:

Frontiers in Medicine

Editorial Office,

Frontiers, Switzerland

*Correspondence:

Alexios-Fotios A. Mentis

amentis1@jhu.edu

tPresent address:

Alexios-Fotios A. Mentis,

Department of Microbiology,

University Hospital of Larissa,

University of Thessaly,

Larissa, Greece

Specialty section:

This article was submitted

to Precision Medicine,

a section of the journal

Frontiers in Medicine

Received: 20 March 2018

Accepted: 23 March 2018

Published: 11 April 2018

Citation:

Mentis AA, Pantelidi K, Dardiotis E,

Hadjigeorgiou GM and Petinaki E (2018) Corrigendum: Precision

Medicine and Global Health: The

Good, the Bad, and the Ugly.

Front. Med. 5:95.

doi: $10.3389 /$ fmed.2018.00095

\section{Alexios-Fotios A. Mentis ${ }^{1 * t}$, Kleoniki Pantelidi ${ }^{2}$, Efthimios Dardiotis ${ }^{3}$, Georgios M. Hadjigeorgiou ${ }^{3}$ and Efthimia Petinaki ${ }^{2}$}

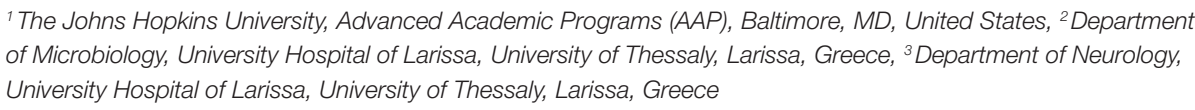

'The Johns Hopkins University, Advanced Academic Programs (AAP), Baltimore, MD, United States, ${ }^{2}$ Department of Microbiology, University Hospital of Larissa, University of Thessaly, Larissa, Greece, ${ }^{3}$ Department of Neurology, University Hospital of Larissa, University of Thessaly, Larissa, Greece

Keywords: precision medicine, genomics, sequencing, big data, global health, health policy, health equity, social determinants of health

\section{A corrigendum on}

Precision Medicine and Global Health: The Good, the Bad, and the Ugly

by Mentis AA, Pantelidi K, Dardiotis E, Hadjigeorgiou GM, Petinaki E. Front Med (2018) 5:67. doi: 10.3389/fmed.2018.00067.

In the original Opinion article, there was an error in the affiliation address of the first and corresponding author.

In the affiliations section, the phrase "American Academy of Pediatrics (AAP)" was mistakenly placed, and it has now been replaced with the correct phrase "Advanced Academic Programs (AAP)." The authors sincerely apologize for the error.

This error does not change the scientific conclusions of the Opinion Article in any way.

The original article has been updated.

Conflict of Interest Statement: The authors declare that the research was conducted in the absence of any commercial or financial relationships that could be construed as a potential conflict of interest.

Copyright ( 2018 Mentis, Pantelidi, Dardiotis, Hadjigeorgiou and Petinaki. This is an open-access article distributed under the terms of the Creative Commons Attribution License (CC BY). The use, distribution or reproduction in other forums is permitted, provided the original author(s) and the copyright owner are credited and that the original publication in this journal is cited, in accordance with accepted academic practice. No use, distribution or reproduction is permitted which does not comply with these terms 